\title{
Chlorogenic acid alters the voltage-gated potassium channel currents of trigeminal ganglion neurons
}

\author{
Yu-Jiao Zhang ${ }^{1, *}$, Xiao-Wen $\mathrm{Lu}^{2}{ }^{2, *}$, Ning Song ${ }^{1}$, Liang Kou ${ }^{2}$, Min-Ke Wu ${ }^{1}$, Fei Liu ${ }^{1}$, Hang Wang ${ }^{1}$ and Jie-Fei Shen ${ }^{1}$ \\ Chlorogenic acid (5-caffeoylquinic acid, CGA) is a phenolic compound that is found ubiquitously in plants, fruits and vegetables and is \\ formed via the esterification of caffeic acid and quinic acid. In addition to its notable biological functions against cardiovascular \\ diseases, type-2 diabetes and inflammatory conditions, CGA was recently hypothesized to be an alternative for the treatment of \\ neurological diseases such as Alzheimer's disease and neuropathic pain disorders. However, its mechanism of action is unclear. \\ Voltage-gated potassium channel $(\mathrm{Kv})$ is a crucial factor in the electro-physiological processes of sensory neurons. Kv has also been \\ identified as a potential therapeutic target for inflammation and neuropathic pain disorders. In this study, we analysed the effects of \\ CGA on the two main subtypes of $K v$ in trigeminal ganglion neurons, namely, the $I_{K, A}$ and $I_{K, V}$ channels. Trigeminal ganglion (TRG) \\ neurons were acutely disassociated from the rat TRG, and two different doses of CGA $\left(0.2\right.$ and $\left.1 \mathrm{mmol} \cdot \mathrm{L}^{-1}\right)$ were applied to the cells. \\ Whole-cell patch-clamp recordings were performed to observe alterations in the activation and inactivation properties of the $I_{K, A}$ and \\ $I_{K, V}$ channels. The results demonstrated that $0.2 \mathrm{mmol} \cdot \mathrm{L}^{-1} \mathrm{CGA}$ decreased the peak current density of $\mathrm{I}_{\mathrm{K}, \mathrm{A}} \cdot \mathrm{Both} 0.2 \mathrm{mmol} \cdot \mathrm{L}^{-1}$ and \\ $1 \mathrm{mmol} \cdot \mathrm{L}^{-1} \mathrm{CGA}$ also caused a significant reduction in the activation and inactivation thresholds of $I_{K, A}$ and $I_{K, V}$. CGA exhibited a \\ strong effect on the activation and inactivation velocities of $I_{K, A}$ and $I_{K, v}$. These findings provide novel evidence explaining the \\ biological effects of CGA, especially regarding its neurological effects. \\ International Journal of Oral Science (2014) 6, 233-240; doi:10.1038/ijos.2014.58; published 14 November 2014
}

Keywords: chlorogenic acid; trigeminal ganglion neuron; voltage-gated potassium channel; whole-cell patch clamp

\section{INTRODUCTION}

Chlorogenic acid (5-caffeoylquinic acid, CGA), the ester of caffeic acid and quinic acid, is primarily extracted from folium cortex eucommiae and the flower buds of lonicera confuse ${ }^{1}$ (Figure 1). As a natural organic phenolic compound, CGA is widely found in numerous botanic species. $^{2}$ As one of the most abundant polyphenol compounds in the human diet, CGA has exhibited various biological effects and therapeutic potential, including antioxidant, ${ }^{3}$ anticarcinogenic ${ }^{4}$ and radioprotective $^{5}$ effects. Novel CGA studies focused on its profound neuroprotective ${ }^{6}$ and neurotrophic activities. ${ }^{7}$ In the early 1970 s, several groups suggested that CGA has a central-stimulating effect $^{8}$ and significantly promotes human central nervous excitement. ${ }^{9}$ Recent studies demonstrated that CGA exhibited protective effects on dopaminergic neurons in neuro-inflammatory conditions associated with Alzheimer's disease. ${ }^{10}$ However, the mechanism underlying the favourable effects of CGA is largely unknown. One possible explanation linked to its oxidant function is that pure CGA suppresses the release of NO from LPS/IFN- $\gamma$-stimulated C6 astrocyte cells, which are crucial mediators in the physiological process of pain. ${ }^{1}$ These experiments were also performed in animal behaviour models to analyse the analgesic effects of CGA on the nervous system.
Voltage-gated potassium channels (Kvs) are the key physiological regulators of membrane potential in sensory neurons. Trigeminal ganglion (TRG) neurons express two distinct classes of Kv currents, including the dominant sustained $\mathrm{K}$-current $\left(\mathrm{I}_{\mathrm{K}, \mathrm{V}}\right)$ and the fast inactivating transient A-current $\left(\mathrm{I}_{\mathrm{K}, \mathrm{A}}\right){ }^{11-12}$ The $\mathrm{I}_{\mathrm{K}, \mathrm{A}}$ channels belong to the Kv 1.4 family ${ }^{13}$ and contribute to neuronal repolarisation and repetitive firing. ${ }^{14}$ The inhibition of this type of channel leads to hyper-excitability and hyperalgesia. ${ }^{15}$ Because $\mathrm{Kv} 1.4$ channels are expressed in the smalldiameter (A $\delta$-, C-fibres) neurons in the dorsal root ganglion, ${ }^{16} \mathrm{I}_{\mathrm{K}, \mathrm{A}}$ plays a significant role in regulating the activity of nociceptive neurons. ${ }^{13}$ By contrast, $\mathrm{I}_{\mathrm{K}, \mathrm{V}}$ channels, which also regulate repetitive firing, are activated with a threshold potential that is more positive than that required for $\mathrm{I}_{\mathrm{K}, \mathrm{A}}$ channels to exhibit delayed long-lasting activation. ${ }^{15} \mathrm{I}_{\mathrm{K}, \mathrm{A}}$ and $I_{K, V}$ can be pharmacologically isolated from whole-cell potassium channel currents due to their different sensitivities to 4-aminopyridine and tetraethylammonium. ${ }^{17}$ For example, $3 \mathrm{mmol} \cdot \mathrm{L}^{-1} 4$-aminopyridine in the extracellular solution demonstrates a preferable inhibition of $\mathrm{I}_{\mathrm{K}, \mathrm{A}}$ compared with $\mathrm{I}_{\mathrm{K}, \mathrm{V}}$, whereas $70 \mathrm{mmol} \cdot \mathrm{L}^{-1}$ tetraethylammonium exhibits the opposite. ${ }^{11} \mathrm{Kv}$ malfunctions contribute to neuronal excitability disorders in various pathologic conditions, such as epilepsy, chronic pain, autism, migraine and multiple sclerosis. ${ }^{11}$

${ }^{1}$ State Key Laboratory of Oral Diseases, West China Hospital of Stomatology, Sichuan University, Chengdu, China and ${ }^{2}$ Ningbo Dental Hospital, Ningbo, China

* These authors contributed equally to this work.

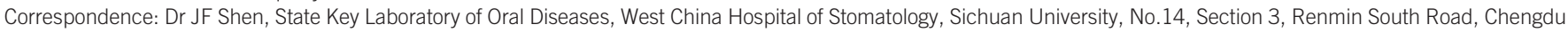
610041, China 


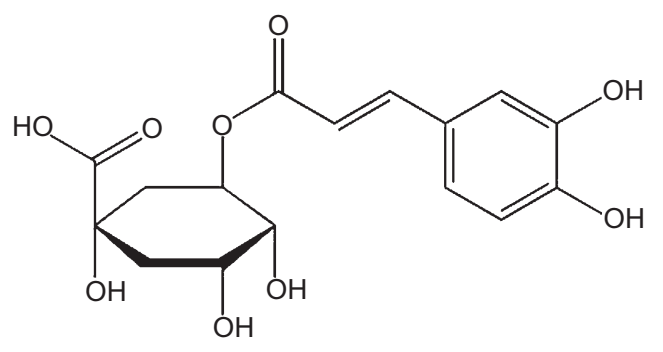

Figure 1 Chemical structure of CGA. CGA, chlorogenic acid.

Given that Kv opening leads to cell membrane hyperpolarisation and a subsequent decrease in cell excitability, several $\mathrm{Kv}$ subtypes have been proposed as potential target candidates for pain therapy. ${ }^{18}$ Additionally, CGA is a novel candidate for the treatment of neuropathic pain. In this study, we determined whether CGA could alter the electrophysiological characteristics of $\mathrm{I}_{\mathrm{K}, \mathrm{A}}$ and $\mathrm{I}_{\mathrm{K}, \mathrm{V}}$ in rat TRG neurons in vivo. Our results provide new evidence explaining the antihyperalgesic effects of CGA, especially in the oral and maxillofacial regions.

\section{MATERIALS AND METHODS}

\section{Acute dissociation of TRG neurons}

All animal procedures were reviewed and approved by the State Key Laboratory of Oral Diseases, Sichuan University. Rat TRG isolation and neurons dissociation were described in our previous reports. ${ }^{11,19}$ Briefly, bilateraltrigeminal ganglia were isolated from neonatal (3-5 days) Sprague-Dawley rats that were anaesthetized with ether. The extracted TRG were washed using ice-cold Hanks' balanced salt solution ( $\mathrm{pH}=7.4$; Sigma-Aldrich China, Shanghai, China), minced into small pieces under a dissecting microscope and incubated in Hanks' balanced salt solution containing $25 \mathrm{U} \cdot \mathrm{mL}^{-1}$ papain (Sigma-Aldrich China, Shanghai, China) at $37{ }^{\circ} \mathrm{C}$ for $40 \mathrm{~min}$. After appropriate digestion, the cells were washed thrice with DMEM/F12 culture medium (1:1 volume; Gibco, Life Technologies, Carlsbad, CA, USA) supplemented with $10 \%$ foetal bovine serum (Gibco, Life Technologies, Carlsbad, CA, USA). Then, the cells were gently triturated using a series of fire-polished Pasteur pipettes and plated on poly- $L$-lysine (SigmaAldrich China, Shanghai, China)-coated glass coverslips placed in $35 \mathrm{~mm}$ dishes (Becton, Dickinson and Company, Franklin Lakes, NJ, USA). The dishes were maintained in a humidified atmosphere of $5 \% \mathrm{CO}_{2}$ at $37{ }^{\circ} \mathrm{C}$ for $2 \mathrm{~h}$ prior to the measurements. All TRG neurons could be distinguished by their distinct larger figures and surrounding halo. The neurons could also be further identified based on Nissl substance stain with cresyl echt violet and electrophysiological characteristics in patch-clamp recordings.

\section{Whole-cell patch-clamp recordings}

Prior to the patch-clamp recordings, the culture medium in the dishes was carefully removed, and the cells were washed thrice with an external solution. The external solution for the $\mathrm{I}_{\mathrm{K}, \mathrm{A}}$ current recordings contained $5 \mathrm{mmol} \cdot \mathrm{L}^{-1} \mathrm{KCl}, 2 \mathrm{mmol} \cdot \mathrm{L}^{-1} \mathrm{CaCl}_{2}, 1 \mathrm{mmol} \cdot \mathrm{L}^{-1}$ $\mathrm{MgCl}_{2}, 70 \mathrm{mmol} \cdot \mathrm{L}^{-1}$ tetraethylammonium (Sigma-Aldrich China, Shanghai, China), $70 \mathrm{mmol} \cdot \mathrm{L}^{-1}$ choline- $\mathrm{Cl}, 10 \mathrm{mmol} \cdot \mathrm{L}^{-1} \mathrm{~d}$-glucose, $10 \mathrm{mmol} \cdot \mathrm{L}^{-1} \quad 4$-(2-hydroxyethyl)-1-piperazineethanesulfonic acid (HEPES) and $0.1 \mathrm{mmol} \cdot \mathrm{L}^{-1} \mathrm{CdCl}_{2}(\mathrm{pH}=7.4)$. For the $\mathrm{I}_{\mathrm{K}, \mathrm{V}}$ recordings, the solution contained $5 \mathrm{mmol} \cdot \mathrm{L}^{-1} \mathrm{KCl}, 2 \mathrm{mmol} \cdot \mathrm{L}^{-1} \mathrm{CaCl}_{2}$, $1 \mathrm{mmol} \cdot \mathrm{L}^{-1} \mathrm{MgCl}_{2}, 3 \mathrm{mmol} \cdot \mathrm{L}^{-1}$ 4-aminopyridine (Sigma-Aldrich China, Shanghai, China), $137 \mathrm{mmol} \cdot \mathrm{L}^{-1}$ choline-Cl, $10 \mathrm{mmol} \cdot \mathrm{L}^{-1} \mathrm{~d}-$ glucose, $10 \mathrm{mmol} \cdot \mathrm{L}^{-1} \mathrm{HEPES}$ and $0.1 \mathrm{mmol} \cdot \mathrm{L}^{-1} \mathrm{CdCl}_{2}(\mathrm{pH}=7.4)$. Finally, the external solution volume in the dishes was adjusted to
$2 \mathrm{~mL}$. Patch-clamp pipettes were pulled from borosilicate glass and filled with an internal solution composed of $120 \mathrm{mmol} \cdot \mathrm{L}^{-1}$ potassium methanesulphonate, $20 \mathrm{mmol} \cdot \mathrm{L}^{-1} \mathrm{KCl}, \quad 7.5 \mathrm{mmol} \cdot \mathrm{L}^{-1}$ HEPES and $2 \mathrm{mmol} \cdot \mathrm{L}^{-1}$ ethylenebis(oxyethylenenitrilo)tetraacetic acid (EGTA) $\left(\mathrm{pH}=7.3\right.$ ) for both the $\mathrm{I}_{\mathrm{K}, \mathrm{A}}$ and $\mathrm{I}_{\mathrm{K}, \mathrm{V}}$ recordings. The mean resistance of the electrodes was 2-4 M $\Omega$. The whole cell recordings were conducted using an Axopatch 200B patch-clamp amplifier (Axon Instruments, Union City, CA, USA), and the output was digitized with the Digidata 1440A converter (Axon Instruments, Union City, CA, USA). Both the capacitance and series resistance were well compensated. All data were acquired using Clampex 10.0 software (Axon Instruments, Union City, CA, USA). All recordings above were performed at a conditioned temperature of $25-26{ }^{\circ} \mathrm{C}$.

Activation and inactivation currents of $\mathrm{Kv}$ subtypes were generated using various stimulus protocols. After achieving a giga-ohm seal between the cell membrane and patch pipette, neurons were initially held at $-80 \mathrm{mV}$ followed by hyperpolarisation to $-80 \mathrm{mV}$ for $70 \mathrm{~ms}$ as a conditioning prepulse potential. The inward $\mathrm{K}^{+}$activation currents were elicited using $100-\mathrm{ms}$ pulses stepping from $-80 \mathrm{mV}$ to $+70 \mathrm{mV}$ in $10-\mathrm{mV}$ increments (Figure $2 \mathrm{a}$ ). The inactivation properties of the $\mathrm{I}_{\mathrm{K}, \mathrm{A}}$ and $\mathrm{I}_{\mathrm{K}, \mathrm{V}}$ were studied using another stimulus protocol. The neurons held at $-80 \mathrm{mV}$ were subject to a series of $250-\mathrm{ms}$ prepulses stepping from $-120 \mathrm{mV}$ to $+50 \mathrm{mV}$ followed by a $250-\mathrm{ms}$ test pulse depolarising to $+50 \mathrm{mV}$ (Figure $2 \mathrm{~b}$ ).

\section{CGA delivery}

Purified CGA was directly dissolved to a final concentration in the extracellular solution and then added to the $35-\mathrm{mm}$ dishes via gravity through a bath perfusion apparatus integrated into the patch-clamp system. Bath solution perfusion was maintained at a rate of $1 \mathrm{~mL} \cdot \mathrm{min}^{-1}$. The perfusion pipette tip was extended as close as possible towards the target neuron without any unfavourable interference with the electrode sealing. All patch-clamp recordings were initiated $30 \mathrm{~s}$ after the perfusion began.

\section{Data analysis}

For $\mathrm{I}_{\mathrm{K}, \mathrm{A}}$ and $\mathrm{I}_{\mathrm{K}, \mathrm{V}}$, current densities were obtained by dividing the peak currents with their own whole-cell capacitances. The channel conductance $(G)$ at various membrane potentials was calculated using the following equation:

$$
G=I /\left(V_{\mathrm{m}}-V_{\text {rev }}\right)
$$

where $I$ represents the current density, $V_{\mathrm{m}}$ represents the voltage command and $V_{\text {rev }}$ represents the reversal potential. Normalized activation curves were plotted as $G / G_{\max }$ against the voltage commands. The curves of all groups were fit to a Boltzmann equation,

$$
G / G_{\max }=1-1 /\left\{1+\exp \left[\left(V_{\mathrm{m}}-V_{1 / 2}\right) / k\right]\right\}
$$

where $V_{\mathrm{m}}$ represents the voltage command, $V_{1 / 2}$ represents the membrane potential at half activation and $k$ represents the slope factor. Their inactivation curves were fit to another Boltzmann equation,

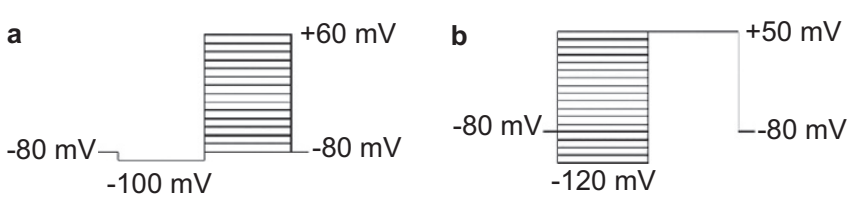

Figure 2 The stimulus protocols of $I_{K, A}$ and $I_{K, V}$. (a) The activation protocol, 100-ms pulses stepping from -80 to $+70 \mathrm{mV}$ in $10-\mathrm{mV}$ increments. (b) The inactivation protocol, 250-ms pre-pulses stepping from -120 to $+50 \mathrm{mV}$ in $10-\mathrm{mV}$ increments. 


$$
I / I_{\max }=1 /\left\{1+\exp \left[\left(V_{\mathrm{m}}-V_{1 / 2}\right) / k\right]\right\}
$$

where $V_{1 / 2}$ represents the membrane potential at half inactivation at this time.

The data were analysed using Clampfit 10.0 software (Axon Instruments, Union City, CA, USA). All curve fittings and statistical comparisons were performed with Origin 9.0 software (OriginLab, Northampton, MA, USA). Differences were considered to be significant at $P<0.05$.

\section{RESULTS}

The small and medium 'nociceptive' TRG and dorsal root ganglion neurons and associated $\mathrm{A} \delta$ - and $\mathrm{C}$-fibre afferents are critical for detecting noxious stimuli and initiating pain sensation. ${ }^{20}$ Therefore, TRG neurons ranging from 15 to $45 \mu \mathrm{m}$ in diameter were selected for further recordings.
Finally, 22 and 18 TRG neurons were randomly selected to obtain the $\mathrm{I}_{\mathrm{K}, \mathrm{A}}$ (11 cells each for the 0.2 and $1.0 \mathrm{mmol} \cdot \mathrm{L}^{-1}$ CGA groups) and $\mathrm{I}_{\mathrm{K}, \mathrm{V}}$ current recordings ( 9 cells each for the 0.2 and $1.0 \mathrm{mmol} \cdot \mathrm{L}^{-1}$ CGA groups), respectively. For every TRG neuron, two complete Kv currents were recorded prior to and after treatment with CGA. In this study, we found that $\mathrm{Kv}$ on TRG neurons initiated activation when the membrane potential was depolarized to approximately $-60 \mathrm{mV}$; the largest current densities were achieved for all four groups at approximately $+70 \mathrm{mV}$.

Effects of the CGA on $I_{K, A}$ and $I_{K, V}$ activation

For $\mathrm{I}_{\mathrm{K}, \mathrm{A}}$, the Boltzmann fitting results demonstrated that both 0.2 and $1 \mathrm{mmol} \cdot \mathrm{L}^{-1}$ CGA caused a significant reduction in the peak current densities and a shift of the activation curves towards a more re-polarisation direction compared with the control group (Figure $3 a$ and $3 b$ ).

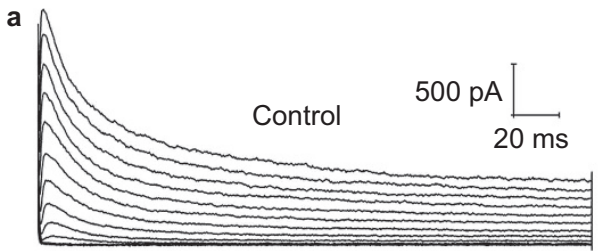

Treated

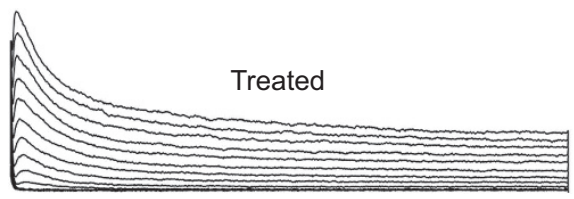

c $V_{1 / 2}$

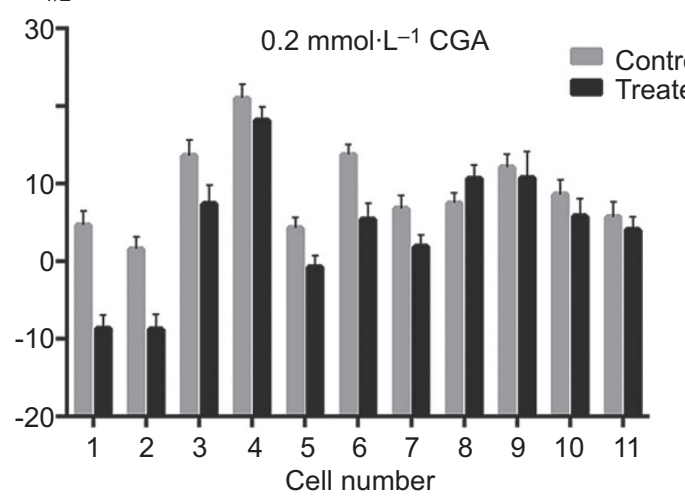

e $V_{1 / 2}$

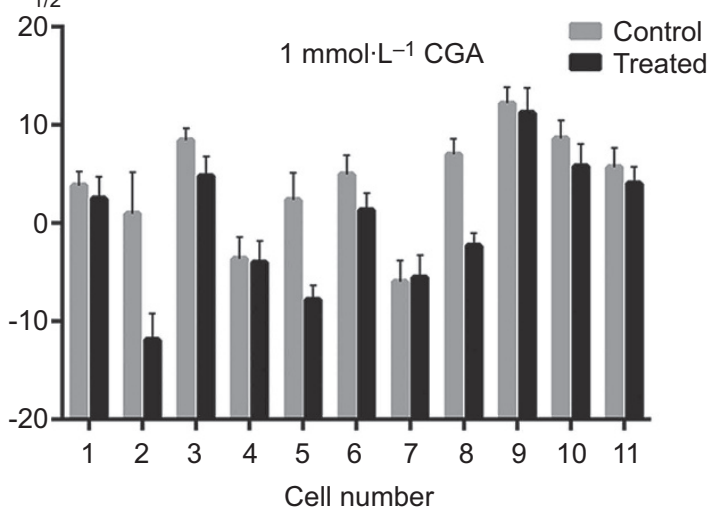

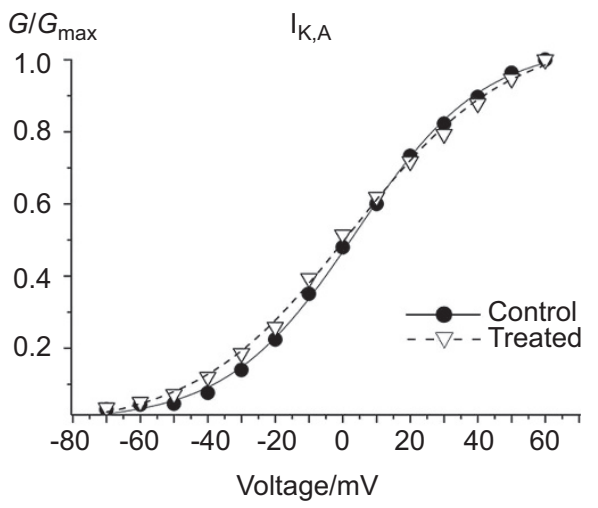
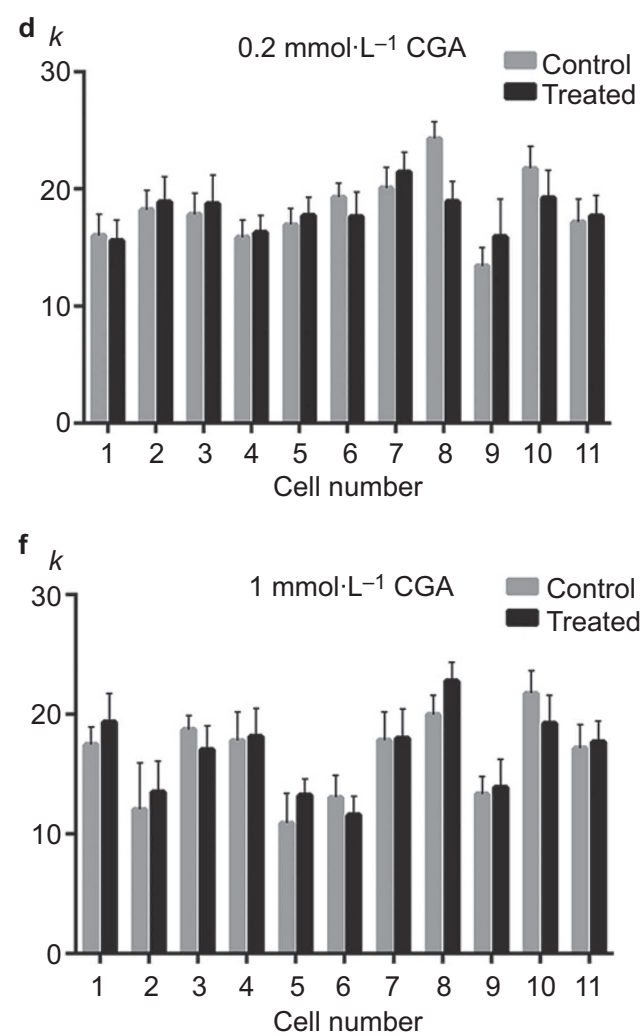

Figure 3 The effects of 0.2 and $1 \mathrm{mmol} \cdot \mathrm{L}^{-1} \mathrm{CGA}$ on the activation of $\mathrm{I}_{\mathbf{K}, \mathbf{A}}$. (a) Typical examples of $\mathrm{I}_{\mathrm{K}, \mathrm{A}}$ activation in the $0.2 \mathrm{mmol} \cdot \mathrm{L}^{-1} \mathrm{CGA}$ treatment and control groups. (b) Normalized $I_{K A}$ activation curves in the $0.2 \mathrm{mmol} \cdot \mathrm{L}^{-1} \mathrm{CGA}$ treatment and control groups. (c, d) Comparison of the fitted results of $I_{K A}$ activation currents between the $0.2 \mathrm{mmol} \cdot \mathrm{L}^{-1} \mathrm{CGA}$ and control groups. (e, f) Comparison of the fitted results of $\mathrm{I}_{\mathrm{K}, \mathrm{A}}$ activation currents between the $1 \mathrm{mmol} \cdot \mathrm{L}^{-1} \mathrm{CGA}$ and control groups. CGA, chlorogenic acid. 
However, no significant differences were noted regarding the change in $V_{1 / 2}$ between the 0.2 and $1 \mathrm{mmol} \cdot \mathrm{L}^{-1}$ CGA groups (Figure $3 \mathrm{c}$ and $3 \mathrm{e})$. More diverse results were obtained for the $k$ value. For the $0.2 \mathrm{mmol} \cdot \mathrm{L}^{-1}$ CGA group, $63.4 \%$ of the TRG neurons exhibited an increase, whereas the remaining neurons exhibited a decrease. These findings led to an overall unchanged result. In the $1.0 \mathrm{mmol} \cdot \mathrm{L}^{-1}$ CGA group, $72.7 \%$ of the cells exhibited an increased $k$ value, which resulted in a similar overall effect (Figure $3 \mathrm{~d}$ and $3 \mathrm{f}$ ).

Although no obvious change on the peak current density of $I_{K, V}$ was noted, the effects of CGA on the $V_{1 / 2}$ of $\mathrm{I}_{\mathrm{K}, \mathrm{V}}$ were generally consistent with those noted for $\mathrm{I}_{\mathrm{K}, \mathrm{A}}$ given that both the 0.2 and $1 \mathrm{mmol} \cdot \mathrm{L}^{-1} \mathrm{CGA}$ groups decreased significantly (Figure $4 \mathrm{c}$ and $4 \mathrm{e})$. Nevertheless, the general effects of 0.2 and $1 \mathrm{mmol} \cdot \mathrm{L}^{-1} \mathrm{CGA}$ on the $k$ value were in opposition. In the 0.2 CGA group, $k$ values in $88.9 \%$ of the TRG neurons exhibited a decrease, whereas the changes caused by $1 \mathrm{mmol} \cdot \mathrm{L}^{-1} \mathrm{CGA}$ were not statistically significant (Figure $4 \mathrm{~d}$ and $4 \mathrm{f}$ ).

The above results imply that treatment with $0.2 \mathrm{mmol} \cdot \mathrm{L}^{-1}$ and $1 \mathrm{mmol} \cdot \mathrm{L}^{-1}$ CGA produce similar effects by activating both $\mathrm{I}_{\mathrm{K}, \mathrm{A}}$ and $\mathrm{I}_{\mathrm{K}, \mathrm{V}}$ channels at a lower threshold. Given that the $k$ value indicates the activation velocity, $1 \mathrm{mmol} \cdot \mathrm{L}^{-1} \mathrm{CGA}$ enables a more rapid

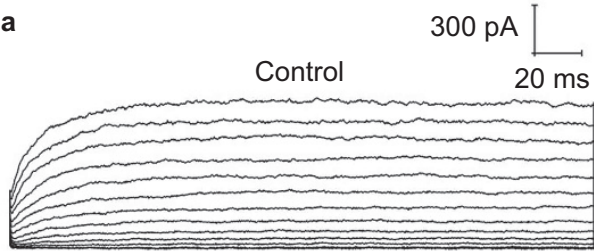

Treated

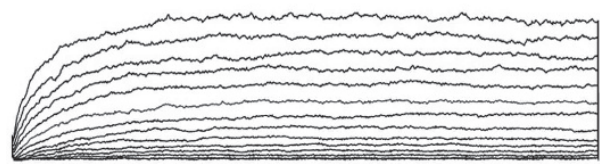

c $V_{1 / 2}$

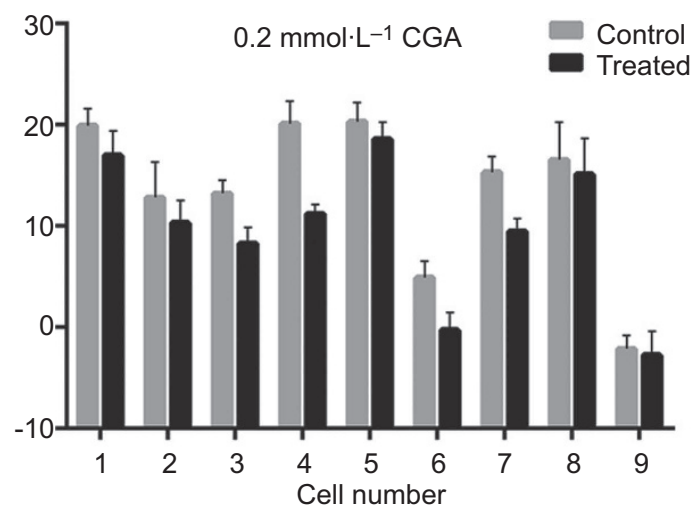

e $V_{1 / 2}$

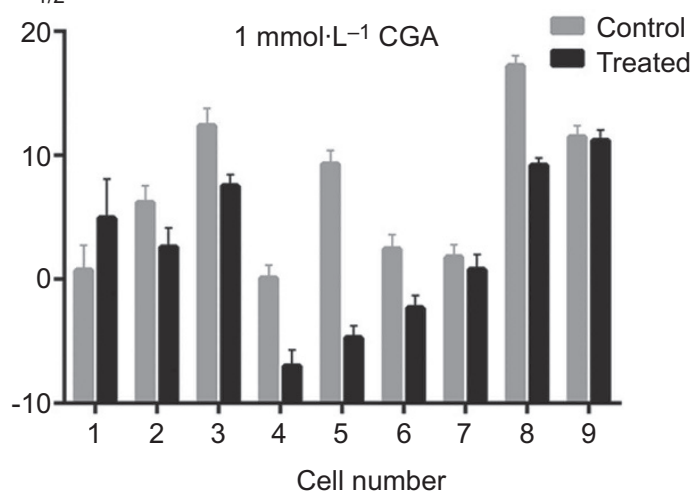

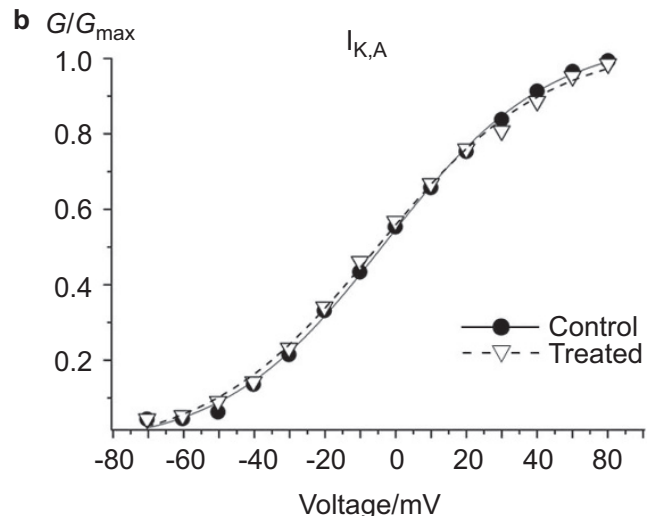

d $k$

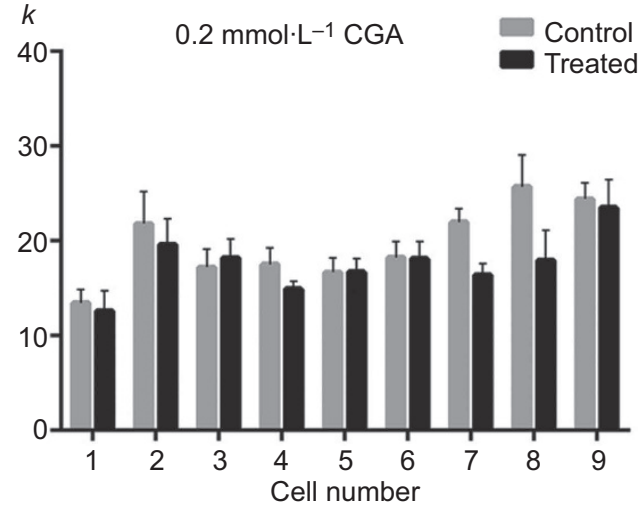

f $k$

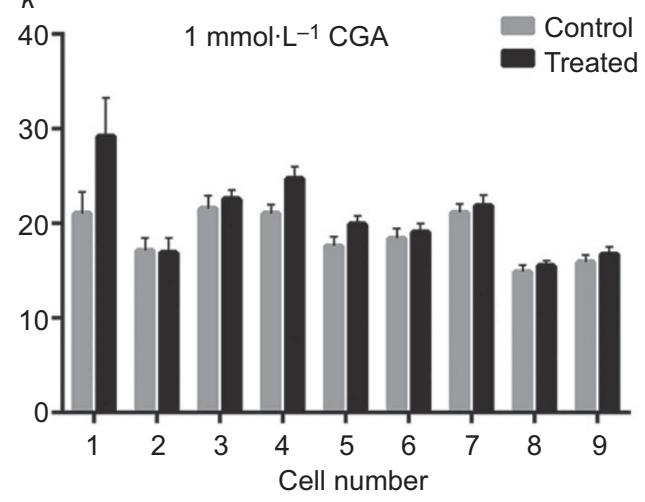

Figure 4 The effects of 0.2 and $1 \mathrm{mmol} \cdot \mathrm{L}^{-1} \mathrm{CGA}$ on the activation of $\mathrm{I}_{\mathrm{K}, \mathrm{v}}$. (a) Typical examples of $\mathrm{I}_{\mathrm{K}, \mathrm{V}}$ activation in the $0.2 \mathrm{mmol} \cdot \mathrm{L}^{-1} \mathrm{CGA}$ and control groups. (b) Normalized $I_{K, V}$ activation curves in the $0.2 \mathrm{mmol} \cdot \mathrm{L}^{-1} \mathrm{CGA}$ and control groups. (c, d) Comparison of the fitted results of $I_{K, V}$ activation currents between the $0.2 \mathrm{mmol} \cdot \mathrm{L}^{-1} \mathrm{CGA}$ and control groups. (e, f) Comparison of the fitted results of the $\mathrm{I}_{\mathrm{K}, \mathrm{V}}$ activation currents between the $1 \mathrm{mmol} \cdot \mathrm{L}^{-1} \mathrm{CGA}$ and control groups. CGA, chlorogenic acid. 
activation of the $\mathrm{I}_{\mathrm{K}, \mathrm{A}}$ channels, whereas $0.2 \mathrm{mmol} \cdot \mathrm{L}^{-1}$ CGA resulted in slower $\mathrm{I}_{\mathrm{K}, \mathrm{V}}$ channel activation.

Effects of CGA on $I_{K, A}$ and $I_{K, V}$ inactivation

With regard to the inactivation characteristics of $\mathrm{I}_{\mathrm{K}, \mathrm{A}}$, both 0.2 and $1 \mathrm{mmol} \cdot \mathrm{L}^{-1} \mathrm{CGA}$ induced a significant reduction in $V_{1 / 2}$ (Figure $5 \mathrm{c}$ and $5 \mathrm{e})$. No significant differences were noted between the 0.2 and $1 \mathrm{mmol} \cdot \mathrm{L}^{-1}$ CGA groups. However, the two CGA doses resulted in opposite effects for the $k$ values (Figure $5 \mathrm{~d}$ and $5 \mathrm{f}$ ). With $0.2 \mathrm{mmol} \cdot \mathrm{L}^{-1} \mathrm{CGA}$, approximately $63.4 \%$ of the TRG neurons
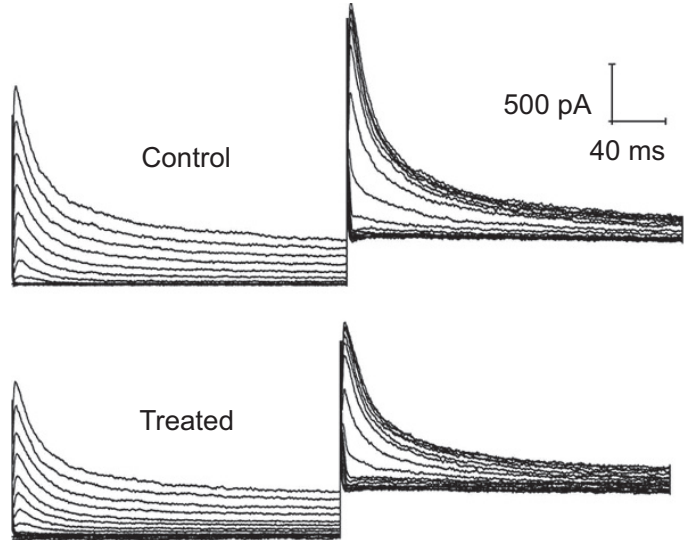

c $V_{1 / 2}$
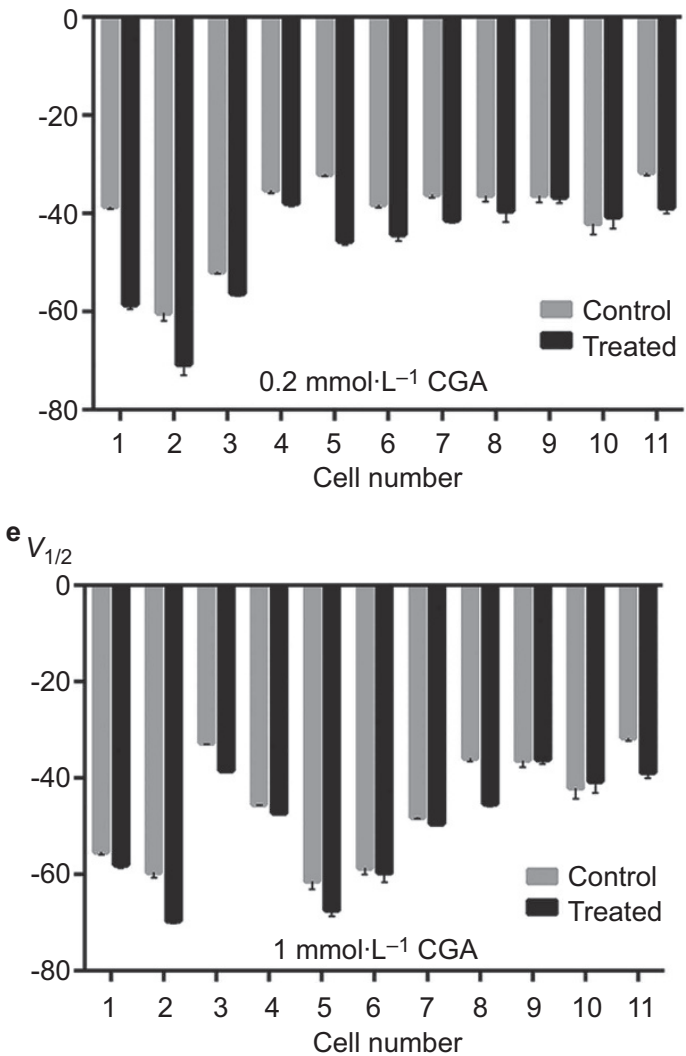

exhibited an increase. With $1.0 \mathrm{mmol} \cdot \mathrm{L}^{-1} \mathrm{CGA}$, only $36.4 \%$ demonstrated a similar outcome.

For $\mathrm{I}_{\mathrm{K}, \mathrm{V}}$, the $V_{1 / 2}$ values also decreased with both 0.2 and $1 \mathrm{mmol} \cdot \mathrm{L}^{-1} \mathrm{CGA}$ (Figure $6 \mathrm{c}$ and $6 \mathrm{e}$ ). However, no significant alteration in the $k$ value was observed when the TRG neurons were treated with 0.2 or $1 \mathrm{mmol} \cdot \mathrm{L}^{-1}$ CGA (Figure 6d and 6f).

The results above indicated that both 0.2 and $1 \mathrm{mmol} \cdot \mathrm{L}^{-1} \mathrm{CGA}$ decreased the inactivation threshold of $\mathrm{I}_{\mathrm{K}, \mathrm{A}}$ and $\mathrm{I}_{\mathrm{K}, \mathrm{V}}$. However, the speed of inactivation appears to increase at a lower CGA concentration and decrease with a higher CGA concentration.
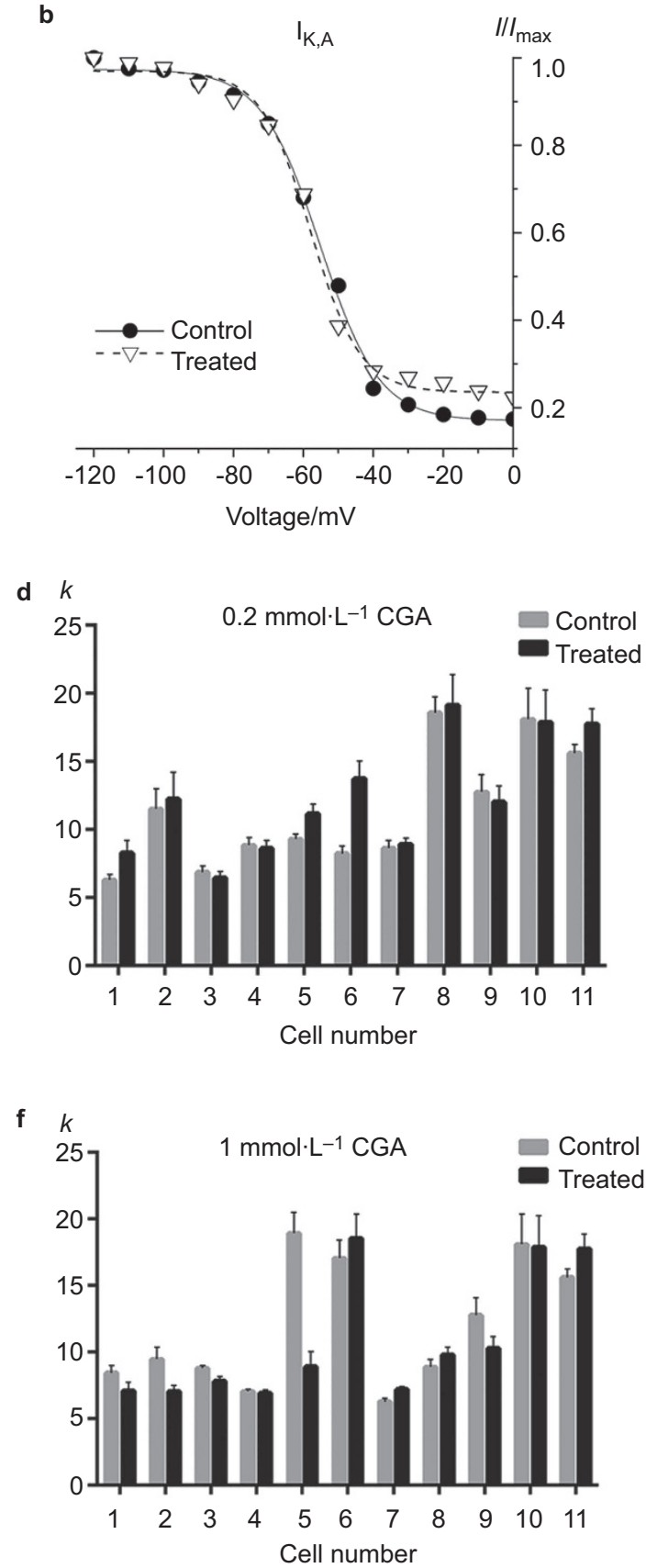

Figure 5 The effects of 0.2 and $1 \mathrm{mmol} \cdot \mathrm{L}^{-1} \mathbf{C G A}$ on $\mathrm{I}_{K, \mathbf{A}}$ inactivation. (a) Typical examples of $\mathrm{I}_{\mathrm{K}, \mathrm{A}}$ inactivation in the $0.2 \mathrm{mmol} \cdot \mathrm{L}^{-1} \mathrm{CGA}$ and control groups. (b) Normalized inactivation curves of $I_{K, A}$ in the $0.2 \mathrm{mmol} \cdot \mathrm{L}^{-1} \mathrm{CGA}$ and control groups. (c, d) Comparison of the fitted results of the $I_{K, A}$ inactivation currents between the $0.2 \mathrm{mmol} \cdot \mathrm{L}^{-1} \mathrm{CGA}$ and control groups. (e, f) Comparison of the fitted results of the $I_{K, A}$ inactivation currents between the $1 \mathrm{mmol} \cdot \mathrm{L}^{-1} \mathrm{CGA}$ and $\mathrm{control}$ groups. CGA, chlorogenic acid. 
a
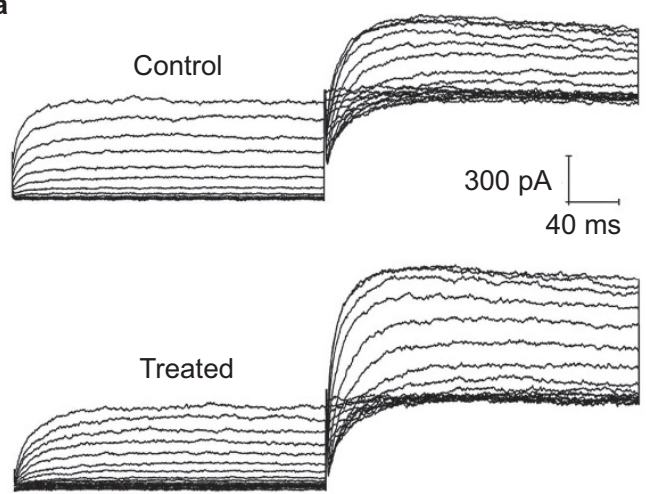

c $V_{1 / 2}$

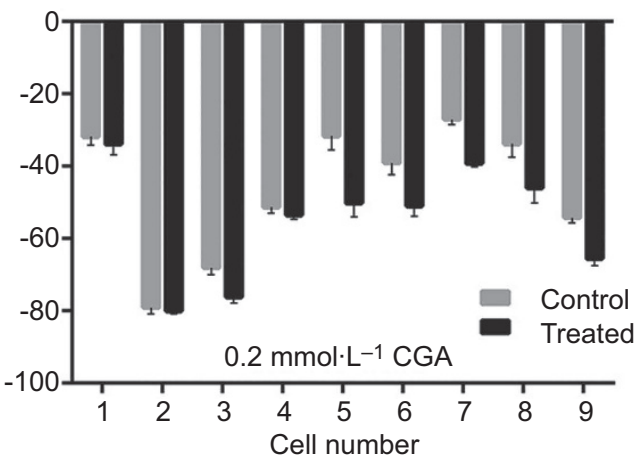

e $\quad V_{1 / 2}$

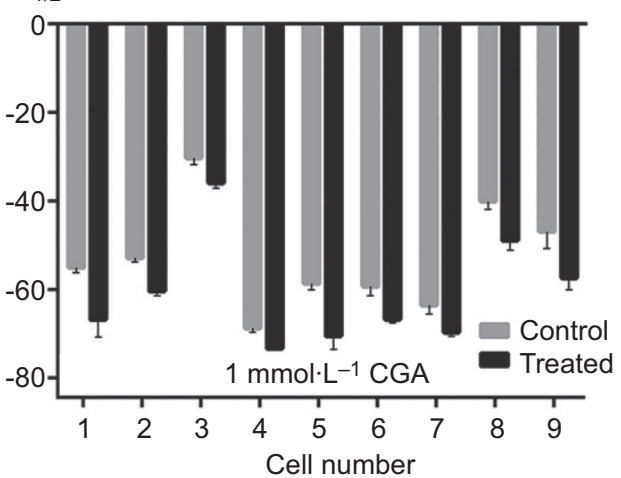

b

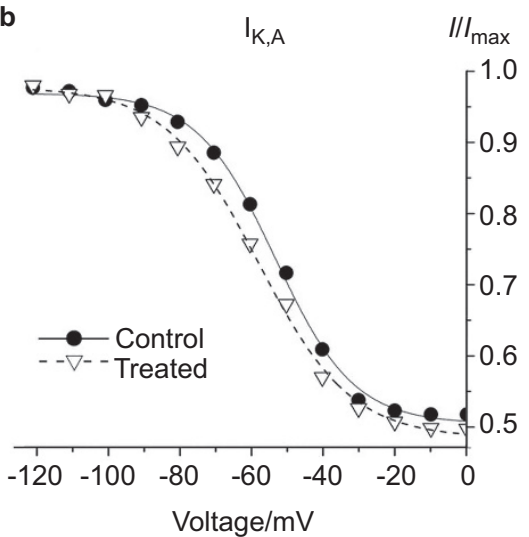

d $k$

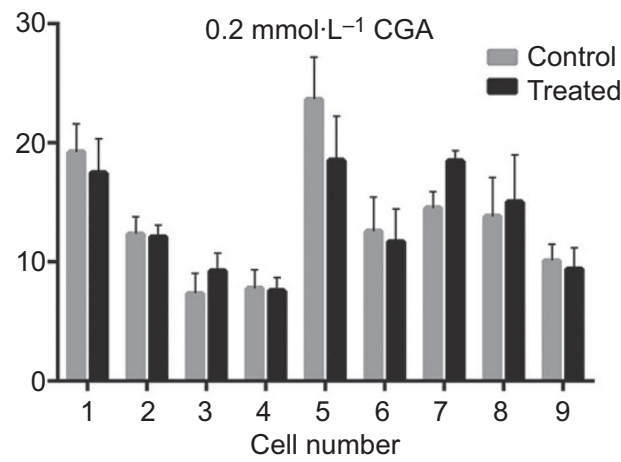

f $k$

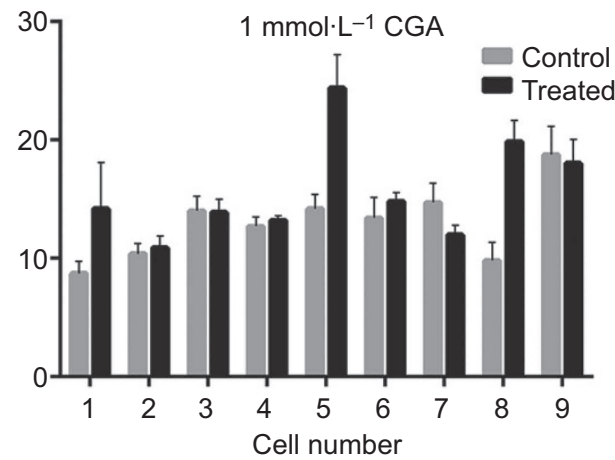

Figure 6 The effects of 0.2 and $1 \mathbf{m m o l} \cdot \mathbf{L}^{-1} \mathbf{C G A}$ on $\mathrm{I}_{\mathbf{K}, \mathbf{v}}$ inactivation. (a) Typical examples of $\mathrm{I}_{\mathrm{K}, \mathrm{V}}$ inactivation in the $0.2 \mathrm{mmol} \cdot \mathrm{L}^{-1} \mathrm{CGA}$ and control groups. (b) Normalized inactivation curves of $I_{K, V}$ in the $0.2 \mathrm{mmol} \cdot \mathrm{L}^{-1} \mathrm{CGA}$ and control groups. (c, d) Comparison of the fitted results of the $I_{K, v}$ inactivation currents between the $0.2 \mathrm{mmol} \cdot \mathrm{L}^{-1} \mathrm{CGA}$ and control groups. (e, f) Comparison of the fitted results of the $I_{\mathrm{K}, \mathrm{V}}$ inactivation currents between the $1 \mathrm{mmol} \cdot \mathrm{L}^{-1} \mathrm{CGA}$ and control groups. CGA, chlorogenic acid.

\section{DISCUSSION}

Multiple types of voltage-gated ion channels constitute the structure and function basis of neuronal excitability in which Kv plays an important role in maintaining the membrane potential, regulating the action potential phase and controlling the firing capacity. ${ }^{18}$ At least two main subtypes of $\mathrm{Kv}$ are present on peripheral sensory neurons (such as dorsal root ganglion and TRG neurons): the fastinactivating transient $\mathrm{I}_{\mathrm{K}, \mathrm{A}}$ and dominant-sustained $\mathrm{I}_{\mathrm{K}, \mathrm{V}} \cdot{ }^{11} \mathrm{I}_{\mathrm{K}, \mathrm{A}}$ and $I_{K, V}$ channels give rise to two distinct channel currents, respectively. Each Kv subtype is composed of distinct subunit combinations, and the $\mathrm{Kv} 1.4,4.2$ and 4.3 subunits are involved in the formation of $\mathrm{I}_{\mathrm{K}, \mathrm{A}}$ and $\mathrm{I}_{\mathrm{K}, \mathrm{V}}$ channels in sensory neurons. ${ }^{16,21}$ Among these, Kv 1.4 is the prominent candidate for a nociceptive interference given that it is highly expressed in small-diameter TRG neurons. ${ }^{22}$ Additionally, the Kv 1.4 family may also directly contribute to the regulation of C-fibre conduction and is particularly important in the treatment of pain. ${ }^{16}$ Reduced Kv 1.4 subunit expression in both myelinated (A $\delta$ fibre type) and unmyelinated (C-fibre type) neurons evokes the hyperactivity of small-diameter TRG neurons. ${ }^{23}$

$\mathrm{Kv}$ was recently considered to be the key factor involved in nociceptive signal transduction induced via inflammatory mediators and nerve damage in primary sensory neurons. Takeda et al. ${ }^{22}$ found that the excitability of rat TRG neurons was enhanced via the decrease of $\mathrm{I}_{\mathrm{K}, \mathrm{A}}$ in temporomandibular joint inflammation. Harriott et al. ${ }^{24}$ also demonstrated that the excitability of masseter muscle afferents was increased by inhibiting $\mathrm{Kv}$ in inflammation 
conditions. The underlying mechanism implicated various inflammation-related cytokines and neurotransmitters that reduced $\mathrm{Kv}$ densities on neurons. Because $\mathrm{I}_{\mathrm{K}, \mathrm{A}}$ and $\mathrm{I}_{\mathrm{K}, \mathrm{V}}$ play different roles in regulating the firing frequency and duration of action potentials in the TRG neurons, alterations in the $\mathrm{Kv}$ subtypes cause an incremental spike discharge and prolonged duration of action potentials in neuropathic or inflammatory pain models. Secondary chain reactions are also elicited during such prolonged durations, including alterations in the amount of neurotransmitter release, the opening of voltage-gated $\mathrm{Ca}^{2+}$ channels and the triggering of the paracrine or autocrine mechanism of neighbouring TRG neurons. Therefore, recent studies have focused on $\mathrm{I}_{\mathrm{K}, \mathrm{A}}$ and $\mathrm{I}_{\mathrm{K}, \mathrm{V}}$ as potential therapeutic targets for trigeminal neuropathic and inflammatory pain. ${ }^{13,16,25-28}$

In our experiment, the activation and inactivation currents of both $I_{K, A}$ and $I_{K, V}$ were significantly shifted toward depolarisation upon CGA treatment, which implies that $\mathrm{Kv}$ is triggered at a lower threshold with a prolonged duration. Thus, the present study was the first to demonstrate that CGA enhances $\mathrm{Kv}$ activities both in $\mathrm{I}_{\mathrm{K}, \mathrm{A}}$ and $\mathrm{I}_{\mathrm{K}, \mathrm{V}}$ channels in rat TG neurons; this would gradually decrease the excitability of neurons in trigeminal hyperalgesic conditions in neuropathic and inflammatory pain. ${ }^{29-31}$

CGAs have been associated with multiple biological effects in recent years, including the reduction of the relative risks of cardiovascular disease and type- 2 diabetes as well as antibacterial and anti-inflammatory functions. ${ }^{32}$ Recent CGA research focused on its application in neurology. In the central neural system, CGA has been considered as a potential drug to treat Alzheimer's disease ${ }^{33-35}$ given that CGA represses NO and TNF- $\alpha$ release in LPS-stimulated primary microglia, which subsequently prevented neurotoxicity caused by microglial activation. $^{6}$ Additionally, CGA exhibits neuroprotective properties in Alzheimer's disease treatment by inhibiting acetylcholinesterase and butyrylcholinesterase activities, as well as preventing oxidative stress-induced neurodegeneration. ${ }^{10}$ CGA also exhibits inhibitory effects on peripheral synthesis and the release of certain inflammatory mediators such as TNF- $\alpha$, NO and several interleukins. ${ }^{1,6,36}$

Interestingly, CGA is also implicated in the modulation of $\mathrm{Kv}$ activity ${ }^{37-40}$ however, the underlying mechanism remains largely unknown. In our study, the activation and inactivation currents of both $I_{K, A}$ and $I_{K, V}$ were significantly shifted to the depolarisation direction upon CGA treatment, which implied that $\mathrm{Kv}$ is triggered at a lower threshold with a prolonged duration. Thus, the present study was the first to demonstrate that CGA enhances Kv activities both in $\mathrm{I}_{\mathrm{K}, \mathrm{A}}$ and $\mathrm{I}_{\mathrm{K}, \mathrm{V}}$ channels in rat TG neurons, thereby gradually decreasing the excitability of neurons in trigeminal hyperalgesic conditions in neuropathic and inflammatory pain. ${ }^{29-31}$

\section{ACKNOWLEDGEMENTS}

We thank Ms Da-Qing Liao, Ms Yan-Fang Chen and Ms Xiao-Yu Li for their technical assistance. This study was supported by the National Science Foundation of China (Grant No. 81000456) and the Science and Technology Department of Sichuan Province (Grant No. 2009SZ0171).

1 dos Santos MD, Almeida MC, Lopes NP et al. Evaluation of the anti-inflammatory, analgesic and antipyretic activities of the natural polyphenol chlorogenic acid. Biol Pharm Bull 2006; 29(11): 2236-2240.

2 Bagdas D, Cinkilic N, Ozboluk HY et al. Antihyperalgesic activity of chlorogenic acid in experimental neuropathic pain. J Nat Med 2013; 67(4): 698-704.

3 Feng R, Lu Y, Bowman LL et al. Inhibition of activator protein-1, NF-kappaB, and MAPKs and induction of phase 2 detoxifying enzyme activity by chlorogenic acid. J Biol Chem 2005; 280(30): 27888-27895.
4 Kang TY, Yang HR, Zhang J et al. The studies of chlorogenic acid antitumor mechanism by gene chip detection: the immune pathway gene expression. J Anal Methods Chem 2013; 2013: 617243.

5 Cinkilic N, Cetintas SK, Zorlu T et al. Radioprotection by two phenolic compounds: chlorogenic and quinic acid, on X-ray induced DNA damage in human blood lymphocytes in vitro. Food Chem Toxicol 2013; 53: 359-363.

6 Shen W, Qi R, Zhang J et al. Chlorogenic acid inhibits LPS-induced microglial activation and improves survival of dopaminergic neurons. Brain Res Bull 2012; 88(5): 487-494.

7 Ito $\mathrm{H}$, Sun $\mathrm{XL}$, Watanabe $\mathrm{M}$ et al. Chlorogenic acid and its metabolite m-coumaric acid evoke neurite outgrowth in hippocampal neuronal cells. Biosci Biotechnol Biochem 2008; 72(3): 885-888.

8 Hach B. Heim F. [Comparative studieson the central stimulating effects of caffeie and chlorogenic acid in white mice.] Arzneimittelforschung 1971; 2: 23-25. German.

9 Ammon HP, Künkel H. [Significance of chlorogenic acid in the centrally-stimulating effect of coffee.] Dtsch Med Wochenschr 1976; 101(12): 460-464. German.

10 Oboh G, Agunloye OM, Akinyemi AJ et al. Comparative study on the inhibitory effect of caffeic and chlorogenic acids on key enzymes linked to Alzheimer's disease and some pro-oxidant induced oxidative stress in rats' brain-in vitro. Neurochem Res 2013; 38(2): 413-419

11 Shen JF, Chao YL, Du L. Effects of static magnetic fields on the voltage-gated potassium channel currents in trigeminal root ganglion neurons. Neurosci Lett 2007; 415(2): 164-168.

12 Takeda M, Takahashi M, Matsumoto S. Inflammation enhanced brain-derived neurotrophic factor-induced suppression of the voltage-gated potassium currents in small-diameter trigeminal ganglion neurons projecting to the trigeminal nucleus interpolaris/caudalis transition zone. Neuroscience 2014; 261: 223-231.

13 Takeda M, Tanimoto $\mathrm{T}$, Ikeda $\mathrm{M}$ et al. Opioidergic modulation of excitability of rat trigeminal root ganglion neuron projections to the superficial layer of cervical dorsal horn. Neuroscience 2004; 125(4): 995-1008.

14 Stewart T, Beyak MJ, Vanner S. Ileitis modulates potassium and sodium currents in guinea pig dorsal root ganglia sensory neurons. J Physiol Lond 2003; 552(Pt 3): 797-807.

15 Pearce RJ, Duchen MR. Differential expression of membrane currents in dissociated mouse primary sensory neurons. Neuroscience 1994; 63(4): 1041-1056.

16 Rasband MN, Park EW, Vanderah TW et al. Distinct potassium channels on painsensing neurons. Proc Natl Acad Sci U S A 2001; 98(23): 13373-13378.

17 Piao L, Lee $\mathrm{H}$, Li $\mathrm{HY}$ et al. Mechanosensitivity of voltage-gated $\mathrm{K}^{+}$currents in rat trigeminal ganglion neurons. J Neurosci Res 2006; 83(7): 1373-1380.

18 Takeda M, Tsuboi Y, Kitagawa J et al. Potassium channels as a potential therapeutic target for trigeminal neuropathic and inflammatory pain. Mol Pain 2011; 7: 5 .

19 Shen J, Wang H, Ma Y et al. [Effects of intracellular osmolality changes on the voltagegated sodium channels currents of trigeminal ganglion neuron.] Hua Xi Kou Qiang Yi Xue Za Zhi 2012; 30(4): 338-342. Chinese.

20 Hampson RE, Evans GJ, Mu J et al. Role of cyclic AMP dependent protein kinase in cannabinoid receptor modulation of potassium "A-current" in cultured rat hippocampal neurons. Life Sci 1995; 56(23/24): 2081-2088.

21 Winkelman DL, Beck CL, Ypey DL et al. Inhibition of the A-type $\mathrm{K}^{+}$channels of dorsal root ganglion neurons by the long-duration anesthetic butamben. J Pharmacol Exp Ther 2005; 314(3): 1177-1186.

22 Takeda M, Tanimoto $\mathrm{T}$, Ikeda $\mathrm{M}$ et al. Temporomandibular joint inflammation potentiates the excitability of trigeminal root ganglion neurons innervating the facial skin in rats. J Neurophysiol 2005; 93(5): 2723-2738.

23 Takeda M, Tanimoto T, Nasu M et al. Temporomandibular joint inflammation decreases the voltage-gated $\mathrm{K}^{+}$channel subtype 1.4-immunoreactivity of trigeminal ganglion neurons in rats. Eur J Pain 2008; 12(2): 189-195.

24 Harriott AM, Dessem D, Gold MS. Inflammation increases the excitability of masseter muscle afferents. Neuroscience 2006; 141(1): 433-442.

25 Takeda M, Kitagawa J, Nasu M et al. Glial cell line-derived neurotrophic factor acutely modulates the excitability of rat small-diameter trigeminal ganglion neurons innervating facial skin. Brain Behav Immun 2010; 24(1): 72-82.

26 Takeda M, Takahashi M, Nasu M et al. Peripheral inflammation suppresses inward rectifying potassium currents of satellite glial cells in the trigeminal ganglia. Pain 2011; 152(9): 2147-2156.

27 Takeda M, Kitagawa J, Takahashi M et al. Activation of interleukin-1beta receptor suppresses the voltage-gated potassium currents in the small-diameter trigeminal ganglion neurons following peripheral inflammation. Pain 2008; 139(3): 594-602.

28 Liu CY, Li N, Zhao YF et al. [BK(Ca) channel agonist NS1619 and Kv channel antagonist 4-AP on the facial mechanical pain threshold in a rat model of chronic constriction injury of the infraorbital nerve.] Sheng Li Xue Bao 2010; 62(5): 441449. Chinese.

29 Everill B, Kocsis JD. Reduction in potassium currents in identified cutaneous afferent dorsal root ganglion neurons after axotomy. J Neurophysiol 1999; 82(2): 700-708.

30 Birinyi-Strachan LC, Gunning SJ, Lewis RJ et al. Block of voltage-gated potassium channels by Pacific ciguatoxin-1 contributes to increased neuronal excitability in rat sensory neurons. Toxicol Appl Pharmacol 2005; 204(2): 175-186.

31 Harriott AM, Gold MS. Contribution of primary afferent channels to neuropathic pain. Curr Pain Headache Rep 2009; 13(3): 197-207.

32 Farah A, Monteiro M, Donangelo CM et al. Chlorogenic acids from green coffee extract are highly bioavailable in humans. J Nutr 2008; 138(12): 2309-2315.

33 Amor S, Puentes F, Baker D et al. Inflammation in neurodegenerative diseases. Immunology 2010; 129(2): 154-169.

34 Block ML, Zecca L, Hong JS. Microglia-mediated neurotoxicity: uncovering the molecular mechanisms. Nat Rev Neurosci 2007; 8(1): 57-69. 
35 Block ML, Hong JS. Microglia and inflammation-mediated neurodegeneration: multiple triggers with a common mechanism. Prog Neurobiol 2005; 76(2): 77-98.

36 Chauhan PS, Satti NK, Sharma $P$ et al. Differential effects of chlorogenic acid on various immunological parameters relevant to rheumatoid arthritis. Phytother Res 2012; 26(8): 1156-1165.

37 Jaffrey SR, Erdjument-Bromage $\mathrm{H}$, Ferris $\mathrm{CD}$ et al. Protein S-nitrosylation: a physiological signal for neuronal nitric oxide. Nat Cell Biol 2001; 3(2): 193-197.

38 Ahern GP, Klyachko VA, Jackson MB. cGMP and S-nitrosylation: two routes for modulation of neuronal excitability by NO. Trends Neurosci2002; 25(10): 510-517.

39 Jiang N, Shi P, Desland F et al. Interleukin-10 inhibits angiotensin II-induced decrease in neuronal potassium current. Am J Physiol Cell Physiol 2013; 304(8): C801-C807.
40 Czeschik JC, Hagenacker T, Schäfers M et al. TNF-alpha differentially modulates ion channels of nociceptive neurons. Neurosci Lett 2008; 434(3): 293-298.

(c) (i) $(5)$ This work is licensed under a Creative Commons Attribution-

cc) NonCommercial-NoDerivs 3.0 Unported License. The images or other third party material in this article are included in the article's Creative Commons license, unless indicated otherwise in the credit line; if the material is not included under the Creative

Commons license, users will need to obtain permission from the license holder to reproduce the material. To view a copy of this license, visit http://creativecommons.org/licenses/ by-nc-nd/3.0/ 